\title{
Strength Properties of PLA Material ObTained by DIFFERENT MODELS OF FDM 3D PRINTER
}

\author{
Adi Pandzic, Damir Hodzic, Ismar Hajro \& Petar Tasic
}
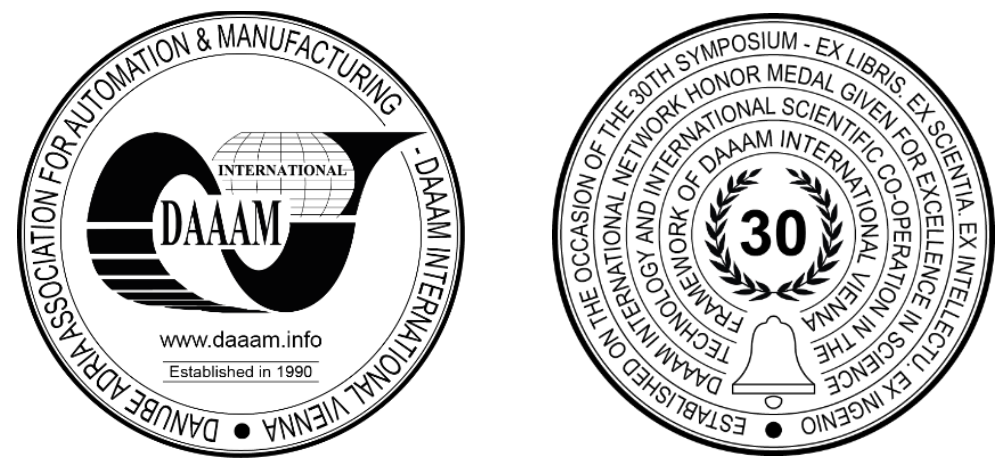

This Publication has to be referred as: Pandzic, A[di]; Hodzic, D[amir]; Hajro, I[smar] \& Tasic, P[etar] (2020). Strength Properties of PLA Material Obtained by Different Models of FDM 3D Printer, Proceedings of the 31st DAAAM International Symposium, pp.0315-0322, B. Katalinic (Ed.), Published by DAAAM International, ISBN 978-3-90273429-7, ISSN 1726-9679, Vienna, Austria

DOI: $10.2507 / 31$ st.daaam.proceedings.044

\begin{abstract}
Additive manufacturing is technology that is widely used to produce good quality products with complex geometries. One of the most popular additive technology today is fused deposition modelling (FDM). Literature review is showing that many parameters have influence on mechanical properties of FDM printed materials. Influence of FDM 3D printer model on strength properties of printed PLA (polylactic acid) material with different infill density is presented in this paper. Testing specimens are printed with five different 3D printer models of the same manufacturer with the same material and 3D printing parameters. Aim was to investigate 3D printer model influence on strength properties of 3D printed PLA material. The results of this study could be useful for users and researchers in order to select appropriate printer model for particular purpose considering optimal relation of PLA material strength properties and FDM 3D printer model.
\end{abstract}

Keywords: FDM; PLA; 3D Print; Strength properties

\section{Introduction}

Additive manufacturing is a process based on layer-upon-layer technique which ultimately forms a 3D geometry. This technology is typically referred to as 3D printing. One of the most commonly used technology for 3D printing is Fused Deposition Modelling (FDM), where a molten thermoplastic material (filament) is laid out layer-by-layer, offering the benefit of producing parts with complex geometry in shorter cycle time and lower costs compared to the traditional manufacturing processes [1], [2], [3]. The FDM process is also known as "Material Extrusion" or Fused Filament Fabrication (FFF).

FDM is a fast-growing additive technology that is used by both hobby users and large manufacturing companies. Common materials that are used by FDM are thermoplastics, e.g. PLA (polylactic acid), ABS (acrylonitrile butadiene styrene), PET (polyethylene terephthalate), PC (polycarbonate), PP (polypropylene) and nylon. In addition, there are some printers that can use composites and metals (Markforged Mark II \& Metal X System). [4] 
FDM 3D printing process is based on pushing thermoplastic filament through feeder into print-head, where filament is melted in a temperature-controlled liquefier, as shown in Fig. 1. The incoming filament acts as a piston, pushing melted material through extrusion nozzle toward the build platform (commonly known as print-bed). A support control system moves the nozzle in the XY plane as the material is deposited on a print-bed. The material is added layer-by-layer in $\mathrm{Z}$ axis direction.

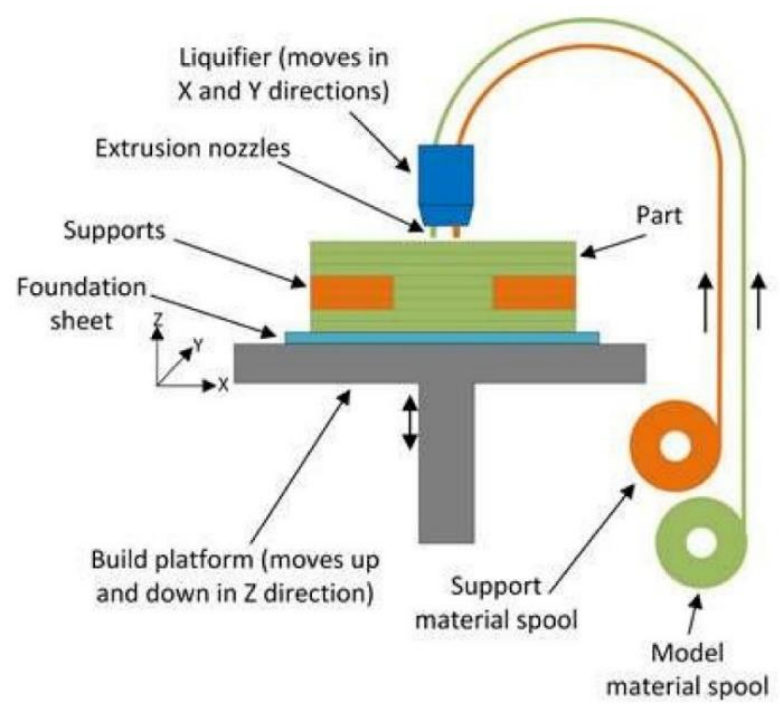

Fig. 1. Schematic of FDM process [5]

Before 3D printing itself, it is necessary to create STL (stereolithography) file from 3D CAD model using CAD software (e.g. Solidworks or Catia). Then G-code with parameters for 3D printing is prepared in slicer software (software for preparing 3D CAD model for 3D printing, e.g. Ultimaker Cura). The movement commands and 3D printing parameters are provided by a G-code file, created by slicer software [6], [7], [8], [9].

Quality and mechanical properties of 3D printed products and printed material depend on properties of filament material, printing parameters, printer quality and environmental factors. From previous studies it can be seen that filament characteristics, build direction, printing speed, infill pattern and density, layer height, nozzle diameter and air gap have influence on product quality and mechanical properties of 3D printed parts [4], [6], [7], [10], [11].

It can be seen from literature that importance is commonly given to influence of process parameters on strength properties of FDM 3D printed material. However, influence of different printer models of the same manufacturer on strength properties of FDM 3D printed material is not evaluated. This could be important in those cases when there are several printers available for printing, and it is necessary to achieve required strength properties of printed material. Among other influential parameters mentioned above, it would be useful to know the scale of difference between certain printers, particularly due to large number of models available on market. Such evaluation would require printing and testing mutually comparable specimens, and therefore all of them should be made using the same printing parameters, the same material from single manufacturer (including colour).

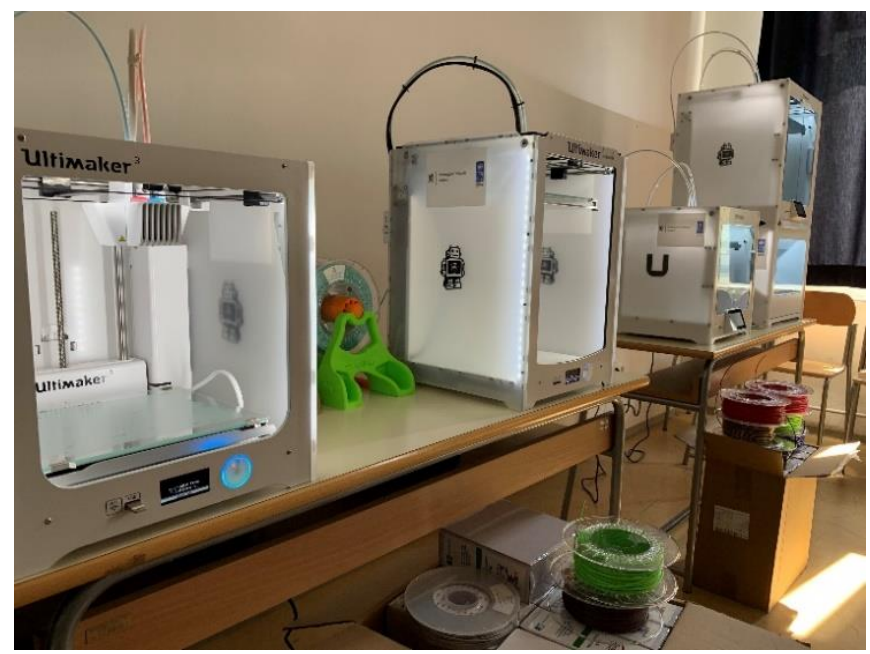

Fig. 2. Ultimaker desktop FDM 3D printers 


\section{Experimental Setup}

This study is based on analysing influence of FDM 3D printer model on tensile properties of PLA material with different infill density. Methodology of preparing 3D model and 3D printed specimens is presented in Fig 3.

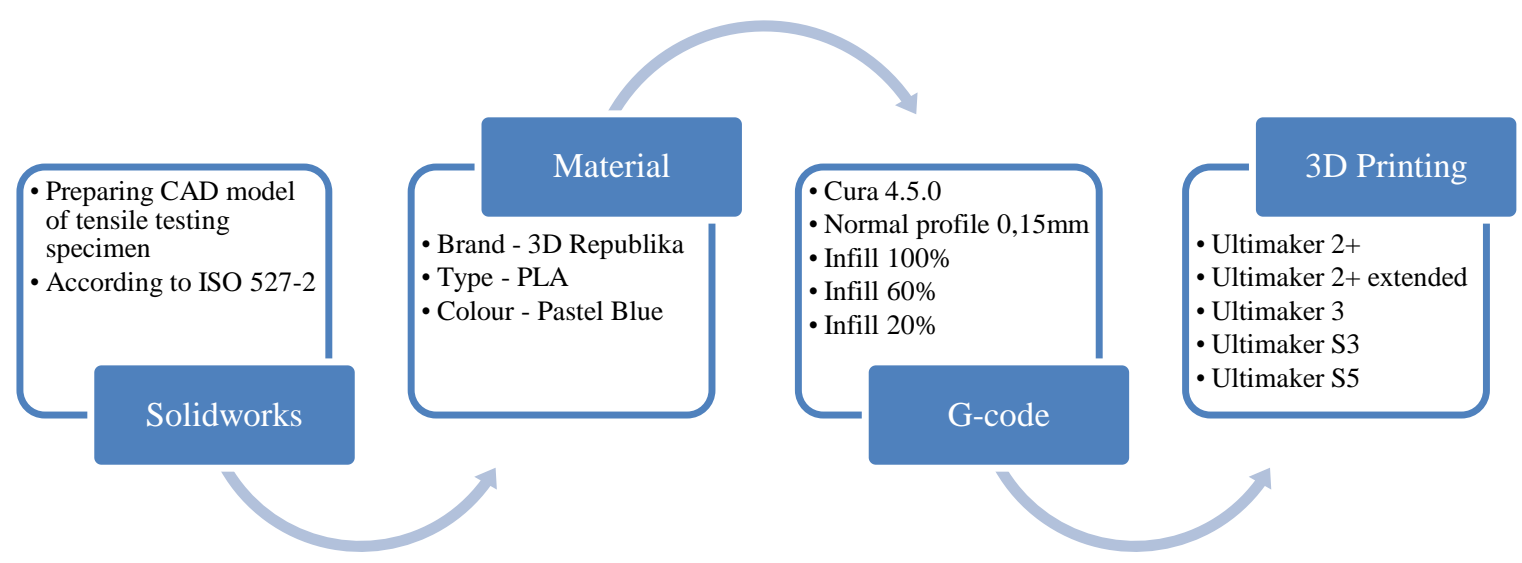

Fig. 3. Methodology of preparing 3D model and 3D printing of tensile testing specimens

Specimens for tensile testing were prepared according to ISO 527-2 with dimensions presented in Fig. 4.

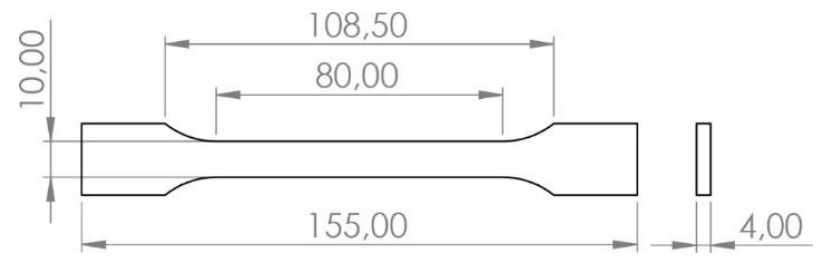

Fig. 4. Tensile testing specimen according to ISO 527-2 standard

3D model of tensile testing specimens was designed in CAD software Solidworks. Afterwards, 3D CAD model of specimen in STL format was used in Cura version 4.5.0 slicer software for preparing G-code and parameters for 3D printing. These steps are shown in Fig. 5.
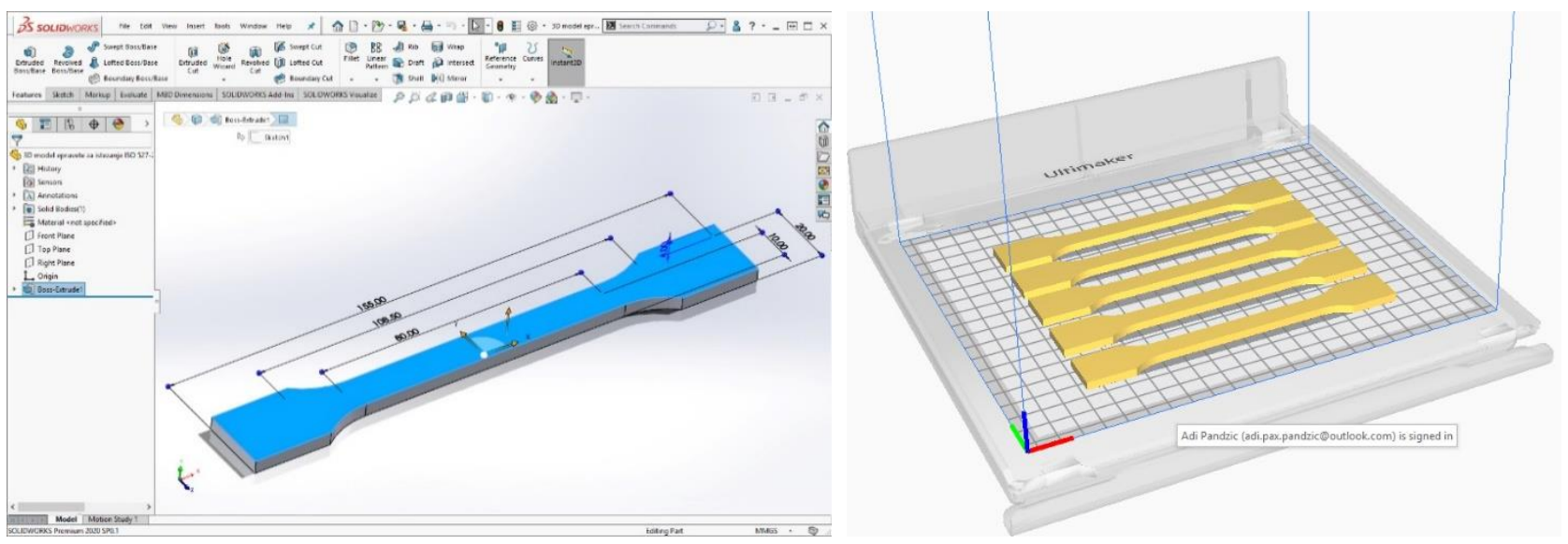

Fig. 5. Tensile testing specimen CAD model in Solidworks (left) and in Cura (right)

All specimens were 3D printed with "Normal profile $0.15 \mathrm{~mm}$ ", predefined printing parameters form Cura software for all 3D printer models, and with nozzle diameter of $0.4 \mathrm{~mm}$. Every 3D printer created specimens with triangle infill shape, $45^{\circ}$ infill angle and with different density $(100 \%, 60 \%$ and $20 \%)$. All specimens were 3D printed in same position 
and "flat" printing orientation (Fig. 6.). In addition, all 3D printers were in same room during work, and were working in same environment (temperature and humidity).
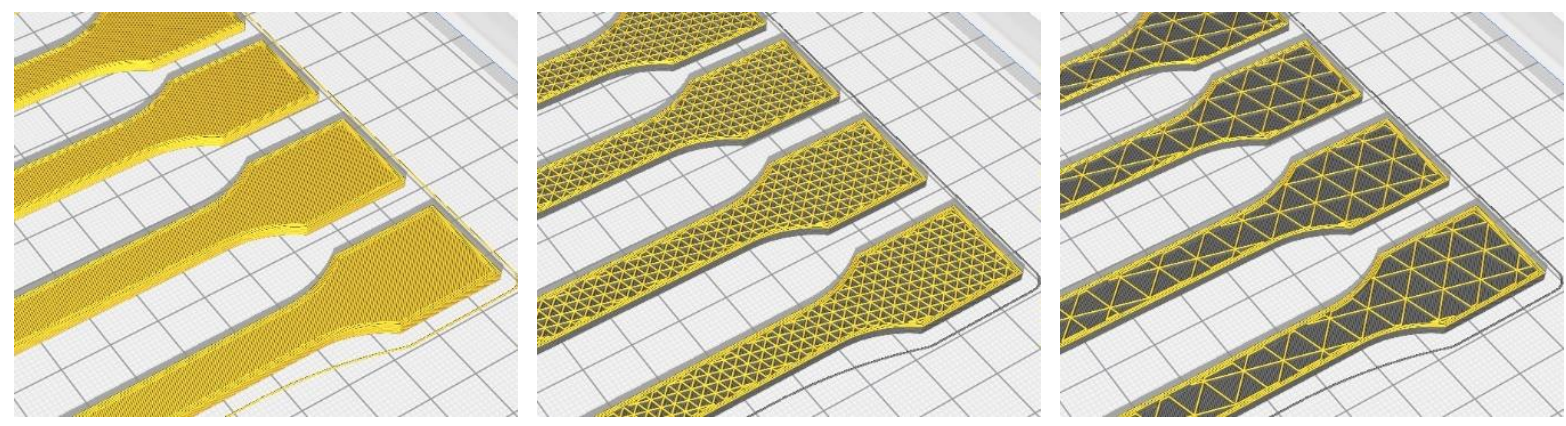

Fig. 6. Tensile testing specimens with different infill density (from left to right $100 \%, 60 \%$ and $20 \%$ )

In this research PLA material from company 3D Republika has been used. Since previous research have shown influence of material colour on mechanical properties of FDM 3D printed material [4], all specimens are printed in "pastel blue" (Fig. 7.). For every infill density and 3D printer model, five specimens have been prepared in accordance with ISO 527-1. Total of 72 specimens have been examined.

Specimens have been tested on Shimadzu AGS-X Std tensile machine with maximal capacity of $10 \mathrm{kN}$, but for this experiment $5 \mathrm{kN}$ load cell has been used, since it has enhanced precision (Fig. 7.).
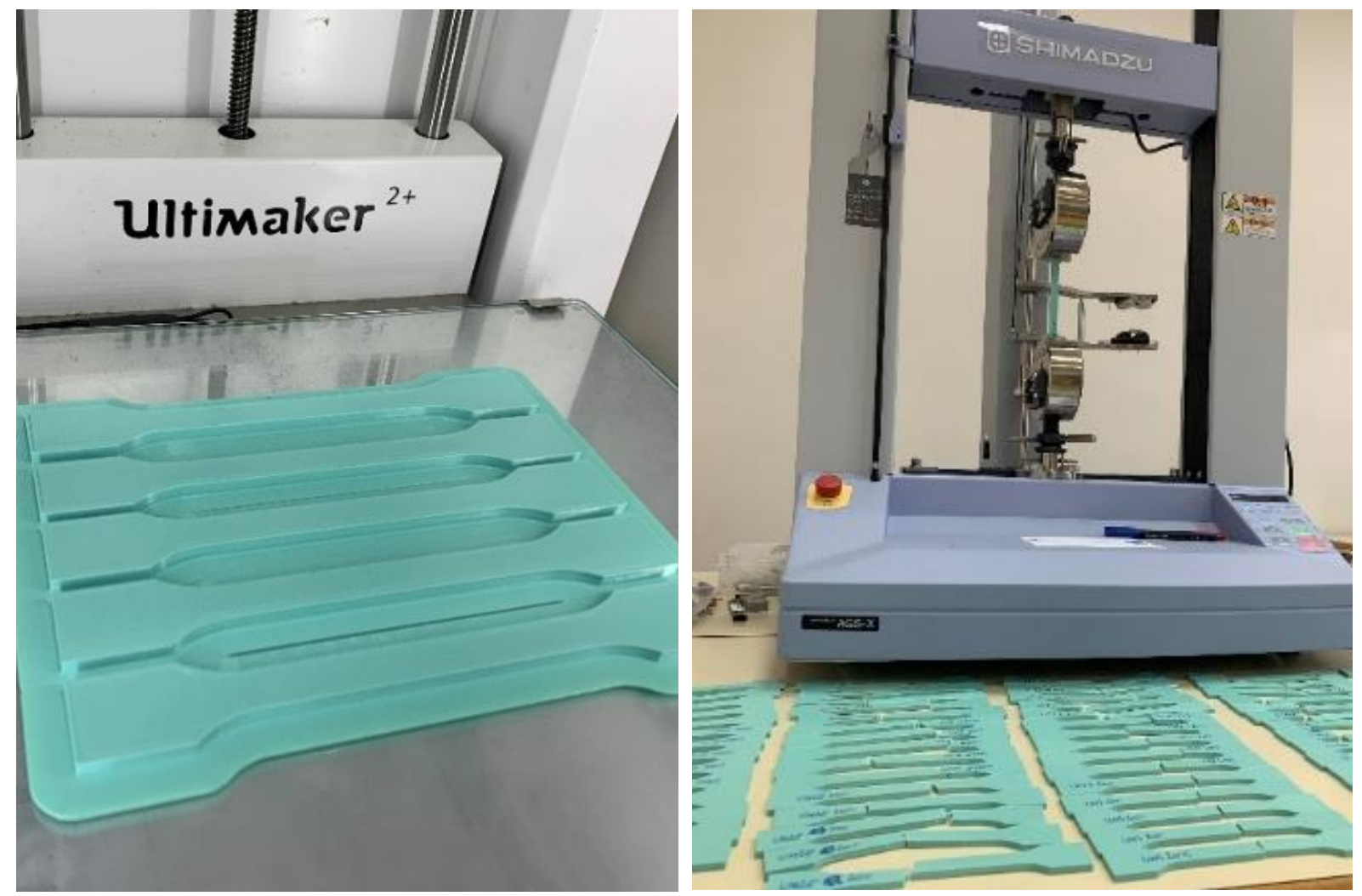

Fig. 7. 3D Printed specimens (left) and testing on Shimadzu AGS-X Std tensile test machine (right)

Monitoring and collecting data was performed using Trapezium-X software. For every specimen, this software plotted stress-strain diagram (Fig. 8.). Tensile testing was performed with strain rate of $5 \mathrm{~mm} / \mathrm{min}$. Collected results are analysed with statistical methods.

\section{Results and discussion}

After testing and collecting all data, stress-strain curves (with average values) were plotted in order to compare strength properties of specimens with various infill densities made with different printer models, as shown in Fig. 8. 

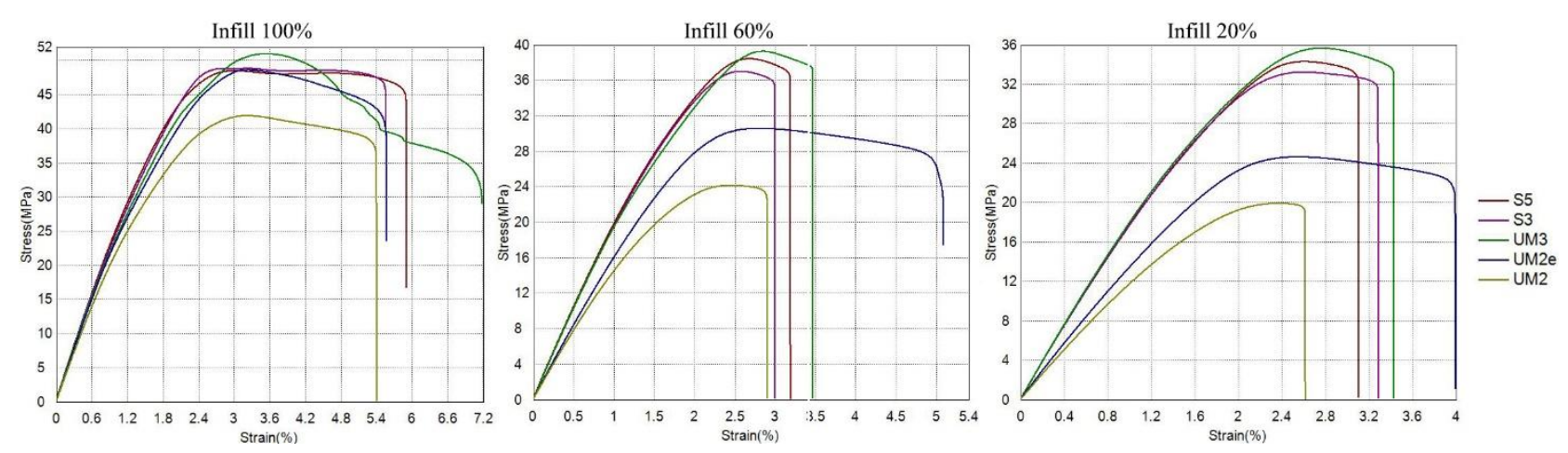

Fig. 8. Stress-strain curves for specimens with different infill density printed on different printer models

In all diagrams can be seen that models Ultimaker 3, S3 and S5 produced material with similar strength properties, with a difference of $5 \mathrm{MPa}$. Ultimaker $2+$ extended printed material achieved similar strength properties to that of Ultimaker 3, S3 and S5 models only for $100 \%$ infill, but for $60 \%$ and $20 \%$ infill these values are lower. Ultimaker $2+$ printed material achieved lowest values of strength properties for every infill density. It was expected that Ultimaker $2+$ and Ultimaker $2+$ extended printed specimens would achieve similar strength properties, since only difference between them is that extended version can print products with larger size in $\mathrm{Z}$ direction (i.e. with increased height). However, test results presented in this paper shown difference. Probable cause of it is that Ultimaker $2+$ is used for 2 years, and other printers (including extended version) are brand new.

It is important to note that tensile stress calculated by software (Fig. 8) is valid for cross-section area of solid specimen. However, for specimens with $60 \%$ and $20 \%$ infill that is not case. Therefore, diagram shown in Fig. 9. gives values of average maximum force $\left(F_{\mathrm{m}}, \mathrm{N}\right)$ before break, for various printers and infill densities, which is parameter considered to be more representative. Hence, it is easier and more reliable to compare differences between strength properties for different Ultimaker 3D printer models.

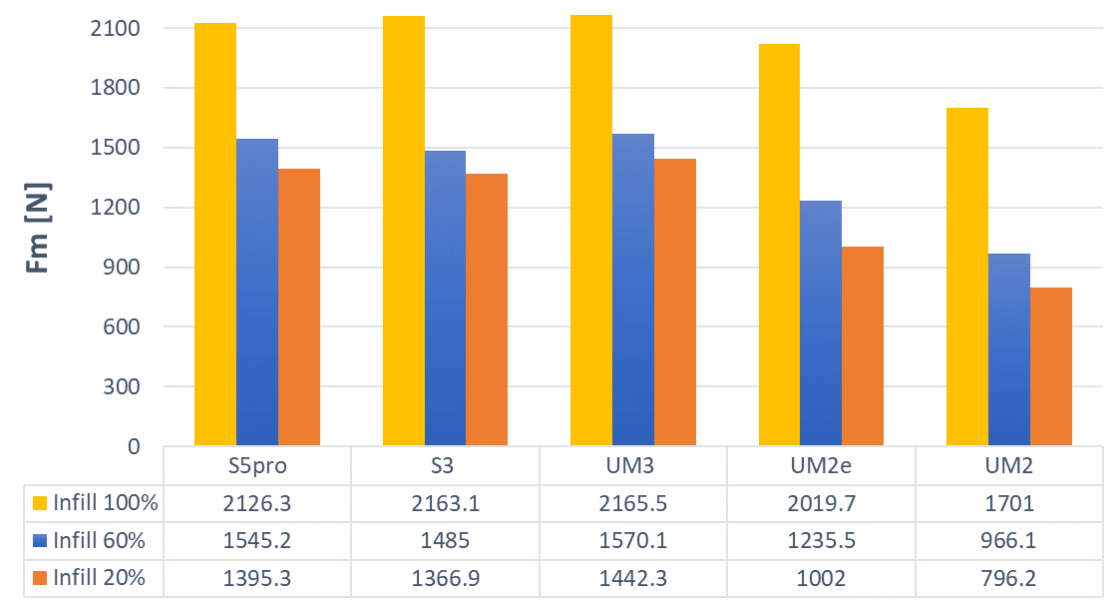

Fig. 9. Average maximum force before break for different infill densities and printer models

Ultimaker 3, S3 and S5 printers are giving small differences in average maximum tensile force before break:

- For infill $100 \%$, difference in $F_{\mathrm{m}}$ is $1.80 \%$,

- For infill $60 \%$, difference in $F_{\mathrm{m}}$ is $5.40 \%$,

- For infill $20 \%$, difference in $F_{\mathrm{m}}$ is $5.20 \%$.

Average maximum force for Ultimaker 2+ extended compared to that of Ultimaker 3, S3 and S5 printers is:

- For infill $100 \%$, difference in $F_{\mathrm{m}}$ is $6.00 \%$.

- For infill $60 \%$, difference in $F_{\mathrm{m}}$ is $19.00 \%$.

- For infill $20 \%$, difference in $F_{\mathrm{m}}$ is $28.00 \%$.

Influence of printer model on strain $(\varepsilon, \%)$ is shown in Fig. 9. 


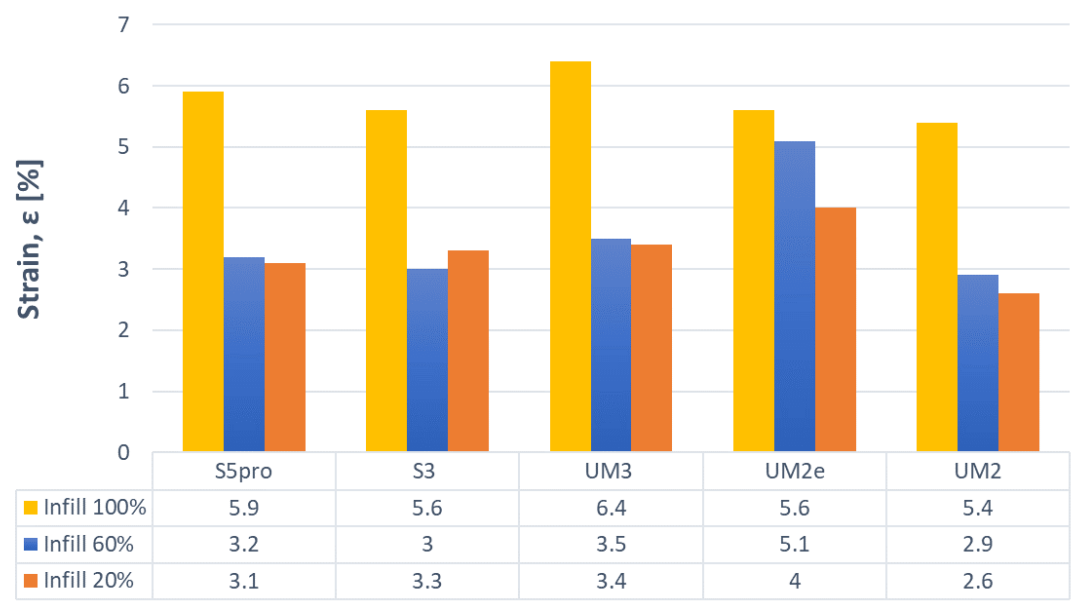

Fig. 10. Average strain before break for different infill densities and printer models

It can be seen that for $100 \%$ infill density Ultimaker 3, S3 and S5 have similar results, with Ultimaker 3 giving slightly higher values of strain (6.40\%). Ultimaker 2 extended shows higher strain for $60 \%$ and $20 \%$ infill density, as well as lowest decrease of strain when comparing specimens with $100 \%$ and $60 \%$ infill density.
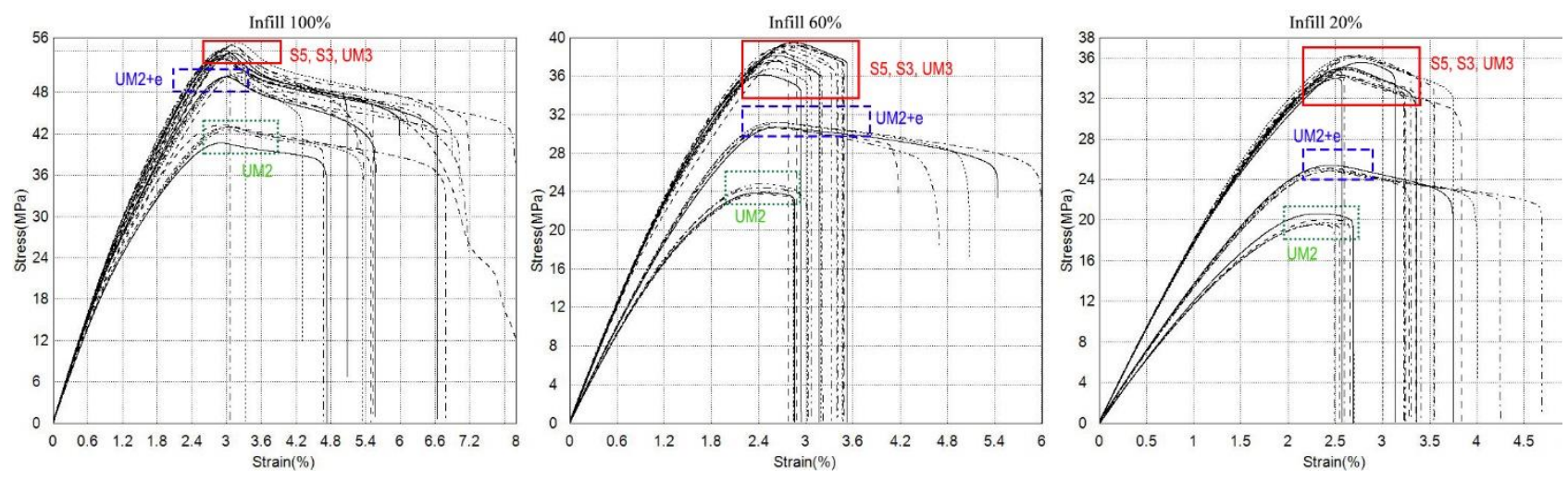

Fig. 11. Stress-strain diagrams of every specimen 3D printed with different infill density and different 3D printer

In addition, very good reproducibility of tests is noticed among all evaluated 3D printer models, with small scattering of results, as possible to see from Fig. 11. Example is also given in Fig. 12. where values of ultimate strength obtained during tests of specimens with $100 \%$ infill density are given for all specimens.

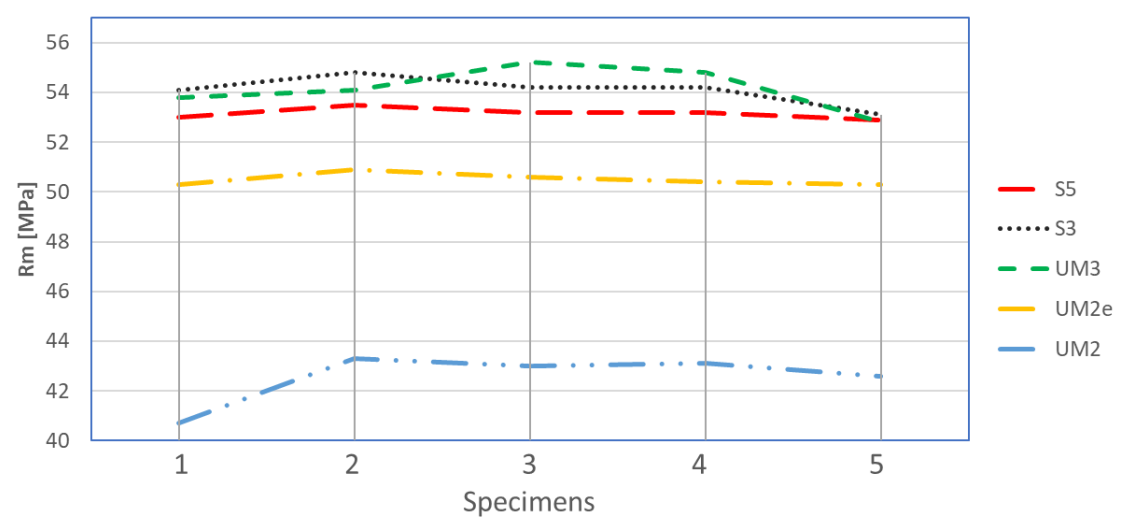

Fig. 12. Ultimate strength for 5 specimens with $100 \%$ infill density printed on different printer models

As stated earlier, all specimens are 3D printed with "normal profile $0.15 \mathrm{~mm}$ ", i.e. with default 3D printing parameters assigned in Cura software for every 3D printer separately (parameters depend on printer model). When analysing "normal profile $0.15 \mathrm{~mm}$ ", differences in 3D printing parameters can be seen, and some of them are presented in Table 1 . 


\begin{tabular}{|l|c|c|c|c|c|c|c|c|}
\hline $\begin{array}{l}\text { Ultimaker } \\
\text { model }\end{array}$ & $\begin{array}{c}\text { Layer } \\
\text { height } \\
{[\mathbf{m m}]}\end{array}$ & $\begin{array}{c}\text { Wall } \\
\text { thickness } \\
{[\mathbf{m m}]}\end{array}$ & $\begin{array}{c}\text { Wall line } \\
\text { count }\end{array}$ & $\begin{array}{c}\text { Top } \\
\text { thickness } \\
{[\mathbf{m m}]}\end{array}$ & $\begin{array}{c}\text { Top } \\
\text { Layers }\end{array}$ & $\begin{array}{c}\text { Bottom } \\
\text { thickness } \\
{[\mathbf{m m}]}\end{array}$ & $\begin{array}{c}\text { Bottom } \\
\text { layers }\end{array}$ & $\begin{array}{c}\text { Print } \\
\text { speed } \\
{[\mathbf{m m} / \mathbf{s}]}\end{array}$ \\
\hline S5 & 0.15 & 1.00 & 3 & 1.00 & 7 & 1.00 & 7 & 70 \\
\hline S3 & 0.15 & 1.00 & 3 & 1.00 & 7 & 1.00 & 7 & 70 \\
\hline 3 & 0.15 & 1.00 & 3 & 1.00 & 7 & 1.00 & 7 & 80 \\
\hline $2+$ ext. & 0.15 & 0.70 & 2 & 0.75 & 5 & 0.75 & 5 & 60 \\
\hline $2+$ & 0.15 & 0.70 & 2 & 0.75 & 5 & 0.75 & 5 & 60 \\
\hline
\end{tabular}

Table 1. Normal profile $0,15 \mathrm{~mm}$ basic 3D printing parameters for different Ultimaker 3D printer models

The data shown in Table 1. gives possible explanation of results elaborated previously in paper. As presented, material printed by Ultimaker 3, S3 and S5 shown higher strength compared to Ultimaker 2+ and 2+ extended. They printed specimens with increased number of boundary layers with increased thickness.

\section{Conclusion}

In this study, influence of 3D printer model on mechanical properties of 3D printed PLA material with different infill density were examined. All printers used in this study were made by Ultimaker. All specimens have been printed after preparation in Cura slicer software with default profile intended to be used with certain printer. Intention was to determine whether printer model has influence on strength properties, while maintaining all other condition the same.

Regarding $R_{\mathrm{m}}$ and $F_{\mathrm{m}}$ values, it is possible to see that Ultimaker 3, S3 and S5 produced specimens with higher $R_{\mathrm{m}}$ and $F_{\mathrm{m}}$ when comparing to Ultimaker 2+ extended and Ultimaker 2+. Results for Ultimaker 3, S3 and S5 indicated small differences in $R_{\mathrm{m}}$ and $F_{\mathrm{m}}$, varying from $1.80 \%$ (infill $100 \%$ ) to $5.40 \%$ (infill $60 \%$ ). Comparing $F_{\mathrm{m}}$ for Ultimaker $2+$ extended with average $F_{\mathrm{m}}$ for Ultimaker 3, S3 and S5 it can be seen that Ultimaker 2+ extended produced specimens with strength properties decreased from $6.00 \%$ (infill 100\%) up to $28.00 \%$ (infill 20\%).

When analysing average strain $(\varepsilon)$, it can be seen that Ultimaker 3, S3 and S5 have similar results, with Ultimaker 3 having slightly higher results $(6.40 \%)$ for infill density $100 \%$. Also, specimens made by Ultimaker 2 extended exhibits higher strain values for $60 \%$ and $20 \%$ infill density. It is interesting to note that specimens made by Ultimaker $2+$ extended have lowest decrease in strain when compared to specimens with $100 \%$ and $60 \%$ infill density. Such relatively significant differences in strength properties among specimens (Fig. 10.) could be explained by variations in printing setup, i.e. set of printing parameters set by Cura slicing software that has been used for printing preparation (Table 1). All specimens were printed with predefined printing parameters, using "normal profile $0.15 \mathrm{~mm}$ " from Cura slicer. On the other side, difference in results between Ultimaker $2+$ extended and Ultimaker $2+$ can be consequence of their age, since Ultimaker $2+$ has been already used for about 2 years, while the other is practically brand new. Nevertheless, it is important to point out reproducibility and reliability of the all used printers.

For future research, it would be recommended to perform similar research, with the same 3D printing parameters (if possible), including those defined with Cura slicing software. In this way, difference caused by default printing profiles could be avoided. Also, all printers used in such evaluation should be the same age with approximately same number of working hours, so possible differences caused by age could be avoided.

\section{References}

[1] Pieter C.; Koeleman L. \& Kuipres T. (2019). The Influence of Infill Patterns With Respect to the Raster Orientation on the Tensile Strength of FDM-Printed PLA, TU Delft \& Ultimaker, unpublished

[2] Kazem F.; Movahedi M. \& Kalman J. (2019). The Impact of Defects on Tensile Properties of 3D Printed Parts Manufactured by Fused Filament Fabrication, Materials Today Communications, Vol. 18, March 2019, pp. 140-148

[3] Farhad M. O.; Abbas T. F. \& Hind B. A. (2018). Influence of Process Parameters on Mechanical Properties and Printing Time of FDM PLA Printed Parts Using Design of Experiment. Journal of Engineering Research and Application, Vol. 8, No. 7., July 2018, pp. 65-69, ISSN: 2248-9622

[4] Pandzic A.; Hodzic D. \& Milovanovic A. (2019). Influence of Material Colour on Mechanical Properties of PLA Material in FDM Technology, Proceedings of the 30th DAAAM International Symposium on Intelligent Manufacturing and Automation, Zadar, ISSN: 1726-9679, ISBN 978-3-902734-22-8, Katalinic, B. (Ed.), pp. 555561, Published by DAAAM International, Vienna, DOI: 10.2507/30th.daaam.proceedings.075

[5] Gebisa A. W. \& Lemu H. G. (2018). Investigating Effects of Fused-Deposition Modeling (FDM) Processing Parameters on Flexural Properties of ULTEM 9085 Using Designed Experiment, Materials, Vol. 11, No. 4, 2018

[6] Pandzic A.; Hodzic D. \& Milovanovic A. (2019). Effect of Infill Type and Density on Tensile Properties of PLA Material for FDM Process, Proceedings of the 30th DAAAM International Symposium on Intelligent Manufacturing and Automation, Zadar, ISSN: 1726-9679, ISBN 978-3-902734-22-8, Katalinic, B. (Ed.), pp. 545-554, Published by DAAAM International, Vienna, DOI: 10.2507/30th.daaam.proceedings.074 
[7] Hodzic D. \& Pandzic A. (2019). Influence of Carbon Fibers on Mechanical Properties of Materials in FDM Technology, Proceedings of the 30th DAAAM International Symposium on Intelligent Manufacturing and Automation, Zadar, ISSN: 1726-9679, ISBN 978-3-902734-22-8, Katalinic, B. (Ed.), pp. 334-342, Published by DAAAM International, Vienna, DOI: 10.2507/30th.daaam.proceedings.044

[8] Cekic A.; Begic-Hajdarevic D.; Muhamedagic K. \& Guzanovic N. (2018). Experimental Investigations of Process Parameters Influence on Dimensional Accuracy and Mechanical Properties of FDM Manufactured Parts, Proceedings of the 29th DAAAM International Symposium on Intelligent Manufacturing and Automation, Zadar, ISSN: 1726-9679, ISBN 978-3-902734-20-4, Katalinic, B. (Ed.), pp. 210-214, Published by DAAAM International, Vienna, DOI: 10.2507/29th.daaam.proceedings.030

[9] Pinero V. D.; Batista P. M.; Valerga A. P.; Vazquez Martinez J. M. \& Fernandez Vidal S. P. (2018). A Comparison of Macro and Microgeometrical Properties of Specimens Made With FDM Commercial Printer and its Opensource Retrofit Version, Proceedings of the 29th DAAAM International Symposium on Intelligent Manufacturing and Automation, Zadar, ISSN: 1726-9679, ISBN 978-3-902734-20-4, Katalinic, B. (Ed.), pp. 1108-1115, Published by DAAAM International, Vienna, DOI: 10.2507/29th.daaam.proceedings.158

[10] Akhoundi B. \& Behravesh A. H. (2018), Effect of Filling Pattern on the Tensile and Flexural and Mechanical Properties of FDM 3D Printed Products, Experimental Mechanics an International Journal, Vol. 11340, December 2018, ISSN 0014-4851

[11] Kumar N.; Jain P. K.; Tandon P. \& Pandey P. M. (2018), The Effect of Process Parameters on Tensile Behaviour of 3D Printed Flexible Parts of Ethylene Vinyl Acetate (EVA), Journal of Manufacturing Processes, Vol. 35, August 2018, pp. 317-326, ISSN 1526-6125 